\title{
Outcomes of robot-assisted laparoscopic radical prostatectomy in high-risk prostate cancer patients: experience in 34 patients with oncologic and functional outcomes
}

\author{
This article was published in the following Dove Press journal: \\ Robotic Surgery: Research and Reviews \\ 16 February 2015 \\ Number of times this article has been viewed
}

\author{
Abdullah Erdem Canda' \\ Ali Fuat Atmaca' \\ Ozer Ural Cakici ${ }^{2}$ \\ Bahri Gok ${ }^{2}$ \\ Muhammed Ersagun Arslan² \\ Serkan Altinova ${ }^{2}$ \\ Ziya Akbulut ${ }^{\prime}$ \\ Mevlana Derya Balbay ${ }^{3}$ \\ 'School of Medicine, Yildirim \\ Beyazit University, Department of \\ Urology, Ankara Ataturk Training \\ and Research Hospital, Ankara, \\ Turkey; ${ }^{2}$ Department of Urology, \\ Ankara Ataturk Training and \\ Research Hospital, Ankara, Turkey; \\ ${ }^{3}$ Department of Urology, Memorial \\ Sisli Hospital, Istanbul, Turkey
}

\begin{abstract}
Introduction: In this retrospective study, we report outcomes of robot-assisted laparoscopic radical prostatectomy (RARP) in high-risk prostate cancer (HRPC) classified according to a D'Amico risk group with minimum 1-year follow-up.

Methods: A total of 34 patients who had at least one preoperative HRPC feature and who underwent RARP were included. Mean patient age and preoperative serum prostate-specific antigen levels were $62.6 \pm 6.4$ years and $12.2 \pm 9.1 \mathrm{ng} / \mathrm{mL}$, respectively. Preoperatively, two $(5.8 \%)$, one $(2.9 \%)$, eleven $(32.3 \%)$, three $(8.8 \%)$, and $17(50 \%)$ patients had prostate biopsy Gleason scores of $5+4,4+5,4+4,3+5$, and $<8$, respectively. Bilateral neurovascular bundle (NVB)-sparing, unilateral NVB-sparing, and non-NVB-sparing surgery was performed in 16 (47\%), five (15\%), and 13 (38\%) patients, respectively.
\end{abstract}

Results: Mean console time, intraoperative blood loss, duration of hospital stay, and urethral catheter removal time were $162.1 \pm 64.4$ minutes, $232.2 \pm 255.1 \mathrm{cc}, 4.1 \pm 2.1$ days, and 12.6 \pm 6.2 days, respectively. During the perioperative period (0-30 days), three minor and five major complications occurred as classified using the modified Clavien classification. No complication was detected during postoperative 31-90 days. Postoperative pathologic stages included pT0, pT2a, pT2b, pT2c, pT3a, and pT3b disease in two (5.8\%), five (14.7\%), three (8.8\%), six (17.6\%), ten (29.4\%), and eight (23.5\%) patients, respectively. Positive surgical margin rate was $32.3 \%$. Mean lymph node yield was $11.8 \pm 8.3$ (range three to 37 ). Mean follow-up was $27.8 \pm 11.1$ months. Biochemical recurrence was detected in nine $(26.4 \%)$ patients. Of the patients, 17 (50\%) were fully continent (zero pads/day), six (17.7\%) wore a safety pad/day, six $(17.7 \%)$ wore one pad/day, three $(8.8 \%)$ wore two pads/day, and two $(5.9 \%)$ wore more than two pads/day. Of the 24 patients with no preoperative erectile dysfunction, 15 (44.1\%) had no erectile dysfunction at a mean follow-up of 1 year. Trifecta and pentafecta rates were $38 \%$ and $26 \%$, respectively.

Conclusion: Based on our experience, RARP in HRPC is a safe procedure with satisfactory oncologic and functional outcomes.

Keywords: robotic radical prostatectomy, high-risk prostate cancer, outcomes, minimally invasive surgery, robotic surgery

\section{Introduction}

Prostate cancer (PCa) accounts for almost $30 \%$ of all newly diagnosed cancers in men in the US and is the second most frequent cause of cancer death in men. ${ }^{1}$ Almost $20 \%-30 \%$ of patients diagnosed with PCa still have high-risk, nonmetastatic disease. ${ }^{2}$ 
D'Amico et $\mathrm{al}^{3}$ proposed a three-group risk stratification system to predict posttreatment biochemical failure following radical prostatectomy (RP) and external-beam radiotherapy. This system classified nonmetastatic $\mathrm{PCa}$ into low-, intermediate-, and high-risk PCa according to initial serum prostate-specific antigen (PSA), clinical T-stage, and biopsy Gleason score. High-risk PCa (HRPC) was classified as having any one of the following features: 1992 American Joint Committee on Cancer stage $\geq \mathrm{T} 2 \mathrm{c}$, PSA $>20 \mathrm{ng} / \mathrm{mL}$, or Gleason disease score of 8-10. ${ }^{3}$

Currently, treatment of HRPC that includes a combination of surgery, radiation therapy, and androgen deprivation therapy as a multimodality approach is controversial.., 5

Management of HRPC requires aggressive treatment; otherwise, this disease might progress and cause serious symptoms and complications and eventually patient death. ${ }^{6}$ The outcomes of the recently published Swedish Registry Study showed that surgery seems to be superior to radiation therapy and longer cancer-specific survival in the surgery group in patients with HRPC as per 15-year cancer-specific survival data ${ }^{7}$ that suggested a trend toward performing RP in HRPC patients. ${ }^{8}$

Although open RP is the standard surgical technique in the surgical management of patients with $\mathrm{PCa}$, a robotic approach has become the most common approach in the US. ${ }^{9}$ However, the number of publications related to the use of robotic surgery in HRPC is very limited.

Herein, we report our experience in RARP and HRPC, including 34 patients classified according to a D'Amico risk group, with minimum 1-year follow-up.

\section{Materials and methods}

Between February 2009 and September 2014, we performed almost 600 RARP procedures at our institution. All the data of the patients were recorded prospectively, and this database was used for our study. Of those, 68 patients were classified as having HRPC according to D'Amico risk groups. Of the patients with HRPC, 34 had at least 1 -year follow-up who were included in the present retrospective study.

All patients in our series were operated on using a da Vinci Surgical System four-arm surgical robot (Intuitive Surgical, Sunnyvale, CA, USA). Overall, five surgeons performed RARP on HRPC patients (AEC, AFA, SA, ZA, and MDB). We previously reported in detail patient preparation, surgical technique, and postoperative follow-up of patients on whom we performed RARP. ${ }^{10}$
Pelvic lymph node (LN) dissection was performed in patients who had $>5 \%$ of LN involvement probability according to Partin's tables. Mean patient age and preoperative serum PSA were $62.6 \pm 6.4$ years and $12.2 \pm 9.1 \mathrm{ng} / \mathrm{mL}$, respectively.

Biochemical recurrence (BCR) was defined as two consecutive serum prostate-specific antigen (PSA) levels of $>0.2 \mathrm{ng} / \mathrm{mL}$.

Statistical analyses were performed with the chi-square test with use of the commercially available software Scientific Package for Social Sciences (SPSS), (version 10.0, Chicago, IL, USA). $P$-values smaller than 0.05 were considered statistically significant.

\section{Results}

Preoperatively, two (5.8\%), one (2.9\%), eleven (32.3\%), three $(8.8 \%)$, and $17(50 \%)$ patients had prostate biopsy Gleason scores of $5+4,4+5,4+4,3+5$, and $<8$, respectively. No patient had a Gleason score of $5+5$ or $5+3$. Bilateral neurovascular bundle (NVB)-sparing, unilateral NVB-sparing, and non-NVB-sparing surgery was performed in 16 (47\%), five (15\%), and 13 (38\%) patients, respectively. Preoperative patient characteristics are presented in Table 1.

Mean console time, intraoperative blood loss, duration of hospital stay, and urethral catheter removal time were $162.1 \pm 64.4$ minutes, $232.2 \pm 255.1 \mathrm{cc}, 4.1 \pm 2.1$ days, and 12.6 \pm 6.2 days, respectively. During the perioperative period ( $0-30$ days), three minor (constipation/prolonged ileus $[n=1]$, prolonged anastomotic leakage $[n=1]$, and urinary tract infection $[\mathrm{n}=1]$ ) and five major complications (intraoperative bladder injury [n=2] and rectum perforation [ $\mathrm{n}=1]$, which were repaired intraoperatively, intensive care requirement $[\mathrm{n}=1]$, and abdominal hematoma $[\mathrm{n}=1]$ ) occurred according to modified Clavien classification. No complication was detected during the postoperative 31-90 days.

Postoperative pathologic stages included pT0, pT2a, pT2b, pT2c, pT3a, and pT3b disease in two (5.8\%), five $(14.7 \%)$, three (8.8\%), six (17.6\%), ten $(29.4 \%)$, and eight $(23.5 \%)$ patients, respectively. No malignancy was detected in two (5.8\%) patients' pathologic specimens. Positive surgical margin (PSM) rate was $32.3 \%$ (2.9\% in pT2 and $29.4 \%$ in pT3 disease). Of the patients, 17 (50\%) underwent extended pelvic LN dissection. Mean LN yield was 11.8 \pm 8.3 (range three to 37). One patient had LN metastasis.

Of the patients, four (11.8\%) received adjuvant radiotherapy (ART) alone, four (11.8\%) received hormone therapy (HT) 
Table I Preoperative patient characteristics

\begin{tabular}{|c|c|}
\hline Patients: $\mathrm{n}(\%)$ & $34(100)$ \\
\hline Mean patient age (years) & $62.6 \pm 6.4(27,49-76)$ \\
\hline Mean BMI $\left(\mathrm{kg} / \mathrm{m}^{2}\right)$ & $26.7 \pm 2.6(11,23-34)$ \\
\hline Mean serum PSA (ng/mL) & $12.2 \pm 9.1(4 \mid, 3.4-45)$ \\
\hline Mean prostate volume (cc) & $52.6 \pm 18.9(73,27-100)$ \\
\hline \multicolumn{2}{|c|}{ Patients with prostate biopsy Gleason scores: $\mathrm{n}(\%)$} \\
\hline $4+4$ & II (32.3\%) \\
\hline $4+5$ & I (2.9\%) \\
\hline $5+4$ & $2(5.8 \%)$ \\
\hline $3+5$ & $3(8.8 \%)$ \\
\hline$<8$ & $17(50 \%)$ \\
\hline $5+5$ & 0 \\
\hline \multicolumn{2}{|l|}{ Preoperative clinical stage: $\mathrm{n}(\%)$} \\
\hline cTI & $4(11.7 \%)$ \\
\hline cT2a & $8(23.5 \%)$ \\
\hline cT2b & $2(5.8 \%)$ \\
\hline cT2c & $20(58.8 \%)$ \\
\hline \multicolumn{2}{|l|}{ Mean ASA score: $n(\%)$} \\
\hline I & II (32.3\%) \\
\hline II & $21(\%)$ \\
\hline III & $2(\%)$ \\
\hline IV & 0 \\
\hline Preoperative mean IIEF score & $36.6 \pm 22.4$ (range $5-75$ ) \\
\hline No ED (IIEF score: 22-25): n (\%) & $24(70.5 \%)$ \\
\hline Mild (IIEF score: I7-2I): n (\%) & 0 \\
\hline Mild to moderate (IIEF score: $12-16): \mathrm{n}(\%)$ & I (2.9\%) \\
\hline Moderate (IIEF score: 8-II): n (\%) & I (2.9\%) \\
\hline Severe (IIEF score: $5-7):$ n (\%) & $8(23.5 \%)$ \\
\hline Preoperative mean IPSS score & $13.5 \pm 6.9$ (range $2-28)$ \\
\hline $\begin{array}{l}\text { Patients with previous abdominal } \\
\text { surgery: } \mathrm{n}(\%)\end{array}$ & $6(17.6 \%)$ \\
\hline \multicolumn{2}{|l|}{ Previous abdominal surgery history: $\mathrm{n}$ (\%) } \\
\hline Inguinal hernia repair & I (2.9\%) \\
\hline Appendectomy & $3(8.8 \%)$ \\
\hline Peptic ulcer perforation & I (2.9\%) \\
\hline TURP & I (2.9\%) \\
\hline
\end{tabular}

Note: Data shown mean $\pm \mathrm{SD}$ (range).

Abbreviations: BMI, body mass index; PSA, prostate-specific antigen; ASA, American Society of Anesthesiologists; IIEF, International Index of Erectile Function; ED, erectile dysfunction; IPSS, International Prostate Symptom Score; TURP, transurethral resection of the prostate.

alone, and four $(11.8 \%)$ received ART + HT postoperatively. Mean follow-up was 27.8 \pm 11.1 months. BCR was detected in nine $(26.4 \%)$ patients. Of the 34 patients with 1 -year follow-up, 17 (50\%) were fully continent (zero pads/day), six $(17.7 \%)$ wore a safety pad/day, six $(17.7 \%)$ wore one $\mathrm{pad} /$ day, three $(8.8 \%)$ wore two pads/day, and two $(5.9 \%)$ wore more than two pads/day. Of the 24 patients with no preoperative erectile dysfunction (ED), 15 (44.1\%) had no erectile dysfunction at a mean follow-up of 1-year. Trifecta and pentafecta rates were $38 \%$ and $26 \%$, respectively.

Operative parameters (Table 2), NVB sparing and relation to PSM (Table 3), postoperative parameters and complications
Table 2 Operative parameters

\begin{tabular}{ll}
\hline Mean surgery (console) time $(\mathrm{min})$ & $\mathrm{I} 62 . \mathrm{I} \pm 64.4$ (range 90-380) \\
Mean estimated blood loss $(\mathrm{cc})$ & $232.2 \pm 255 . \mathrm{I}$ (range 40-I,500) \\
APAs detected and preserved: $\mathrm{n}(\%)$ & \\
Overall & $4(1 \mathrm{I.7 \%})$ \\
Unilateral & $3(8.8 \%)$ \\
Bilateral & $\mathrm{I}(2.9 \%)$ \\
Not preserved & 0 \\
NVB-preserving technique: $\mathrm{n}(\%)$ & \\
Bilateral & $16(47 \%)$ \\
Unilateral & $5(15 \%)$ \\
Not performed & $\mathrm{I}(38 \%)$ \\
\hline
\end{tabular}

Abbreviations: APA, accessory pudendal artery; NVB, neurovascular bundle.

classified according to modified Clavien-Dindo classification (Table 4), postoperative pathologic outcomes (Table 5), oncologic outcomes (Table 6), postoperative urinary continence outcomes (Table 7), postoperative erectile function outcomes (Table 8), and trifecta and pentafecta outcomes (Table 9) are presented.

\section{Discussion}

RARP is increasingly being applied in the surgical management of PCa; however, number of publications related to experience in HRPC is limited. In this paper, we evaluated the outcomes of our RARP experience in 34 HRPC patients.

In our series, mean estimated blood loss was $232.2 \mathrm{cc}$. Similar to our study, Punnen et al ${ }^{11}$ reported estimated blood loss as $217 \mathrm{cc}$ in a series of 233 HRPC patients, respectively, who underwent RARP. Mean length of hospital stay was 4.1 days in our series. On the other hand, Punnen et $\mathrm{a}^{11}$ and Gandaglia et $\mathrm{al}^{12}$ reported a shorter length of hospital stay as 1.6 days and 1 day, respectively. In our study, mean length of hospital stay seems to be longer than that in Punnen et $\mathrm{al}^{11}$ and Gandaglia et al. ${ }^{12}$ We discharge patients when we remove the abdominal drain, generally on postoperative day 3 or 4 , and when the patient passes flatus and initiates sufficient oral intake.

Table 3 NVB sparing and relation to PSM

\begin{tabular}{|c|c|c|c|}
\hline & $\begin{array}{l}\text { Bilateral } \\
\text { NVB sparing }\end{array}$ & $\begin{array}{l}\text { Unilateral } \\
\text { NVB sparing }\end{array}$ & $\begin{array}{l}\text { Non-NVB } \\
\text { sparing }\end{array}$ \\
\hline Overall $\mathrm{N}=34$ & $\mathrm{~N}=16,47 \%$ & $N=5,15 \%$ & $\mathrm{~N}=13,38 \%$ \\
\hline PSM & $\mathrm{N}=6,40 \%$ & $\mathrm{~N}=\mathrm{I}, 20 \%$ & $\mathrm{~N}=4,30.7 \%$ \\
\hline \multicolumn{4}{|l|}{ PSM location } \\
\hline Apex & $\mathrm{N}=2,13.3 \%$ & $\mathrm{~N}=\mathrm{I}, 20 \%$ & $\mathrm{~N}=\mathrm{I}, 7.6 \%$ \\
\hline Prostate base & $\mathrm{N}=4,26.6 \%$ & $\mathrm{~N}=0$ & $\mathrm{~N}=2,15.3 \%$ \\
\hline $\begin{array}{l}\text { Bilateral prostate } \\
\text { laterale lobes }\end{array}$ & $\mathrm{N}=0$ & $\mathrm{~N}=0$ & $\mathrm{~N}=\mathrm{I}, 7.6 \%$ \\
\hline
\end{tabular}

Abbreviations: NVB, neurovascular bundle; PSM, positive surgical margin. 
Table 4 Postoperative parameters and complications classified according to modified Clavien-Dindo classification

\begin{tabular}{|c|c|c|}
\hline Mean follow-up (months) & \multicolumn{2}{|c|}{$27.8 \pm 11.1$ (range I2-48) } \\
\hline $\begin{array}{l}\text { Mean abdominal drain removal } \\
\text { time (days) }\end{array}$ & \multicolumn{2}{|c|}{$3 . I \pm 2.0$ (range $I-12)$} \\
\hline $\begin{array}{l}\text { Mean urethral catheter removal } \\
\text { time (days) }\end{array}$ & \multicolumn{2}{|c|}{$12.6 \pm 6.2$ (range $7-30)$} \\
\hline $\begin{array}{l}\text { Mean duration of hospital } \\
\text { stay (days) }\end{array}$ & \multicolumn{2}{|c|}{$4.1 \pm 2.1$ (range $2-12)$} \\
\hline Type of complication & $0-30$ days & $31-90$ days \\
\hline \multicolumn{3}{|l|}{ Intraoperative (surgical) } \\
\hline Bladder perforation & 2 (Clavien 3b) & None \\
\hline Rectum perforation & I (Clavien 3b) & None \\
\hline \multicolumn{3}{|l|}{ Postoperative } \\
\hline Wound & None & None \\
\hline Pulmonary & None & None \\
\hline Neurologic & None & None \\
\hline \multicolumn{3}{|l|}{ Gastrourinary } \\
\hline Urinary leakage & I (Clavien I) & None \\
\hline Infectious diseases & None & None \\
\hline Urinary infection & I (Clavien 2) & None \\
\hline \multicolumn{3}{|l|}{ Gastrointestinal } \\
\hline Constipation & I (Clavien I) & None \\
\hline Cardiac & None & None \\
\hline \multicolumn{3}{|l|}{ Bleeding } \\
\hline Abdominal hematoma & I (Clavien 3b) & None \\
\hline Thromboembolic & None & None \\
\hline Uremia & None & None \\
\hline Metabolic & None & None \\
\hline Psychiatric & None & None \\
\hline Miscellaneous & None & None \\
\hline Intensive care requirement & I (Clavien 4) & None \\
\hline $\begin{array}{l}\text { Grade of complications } \\
\text { according to modified } \\
\text { Clavien-Dindo classification: } n\end{array}$ & $\begin{array}{l}\text { Overall } \\
\text { complications: } \\
\mathrm{N}=\mathbf{8}\end{array}$ & $\begin{array}{l}\text { Overall } \\
\text { complications: } \\
\mathrm{N}=0\end{array}$ \\
\hline I & 2 & 0 \\
\hline 2 & I & 0 \\
\hline 3a & 0 & 0 \\
\hline $3 b$ & 4 & 0 \\
\hline 4 & I & 0 \\
\hline 5 & 0 & 0 \\
\hline Minor complication (grade I and 2): $\mathrm{n}$ & 3 & 0 \\
\hline Major complication (grade 3-5): n & 5 & 0 \\
\hline $\begin{array}{l}\text { Readmission due to minor } \\
\text { complications: } \mathrm{n}\end{array}$ & I & 0 \\
\hline $\begin{array}{l}\text { Readmission due to major } \\
\text { complications: } \mathrm{n}\end{array}$ & 0 & 0 \\
\hline
\end{tabular}

In our series, 17 patients (50\%) underwent extended pelvic $\mathrm{LN}$ dissection and mean $\mathrm{LN}$ yield was 11.8. One patient had LN metastasis. We performed bilateral extended pelvic $\mathrm{LN}$ dissection in those with an at least $5 \%$ risk of pelvic $\mathrm{LN}$ involvement by $\mathrm{PCa}$ according to Partin's tables. ${ }^{13}$ Harty et $\mathrm{al}^{14}(\mathrm{n}=152)$, Pierorazio et $\mathrm{a}^{15}(\mathrm{n}=105)$, Punnen et $\mathrm{al}^{11}$ $(\mathrm{n}=233)$, Busch et $\mathrm{a} \mathbf{~}^{16}(\mathrm{n}=110)$, and Gandaglia et $\mathrm{a}^{12}(\mathrm{n}=806)$ performed pelvic $\mathrm{LN}$ dissection in $56 \%, 97.1 \%, 63 \%, 94.5 \%$,
Table 5 Postoperative pathologic outcomes

\begin{tabular}{ll}
\hline Pathologic stage & $\mathrm{N}=34(\mathrm{I} 00 \%)$ \\
ASAP + HGPIN & 0 \\
PT0 & $2(5.8 \%)$ \\
PT2a & $5(14.7 \%)$ \\
PT2b & $3(8.8 \%)$ \\
PT2c & $6(17.6 \%)$ \\
PT3a & $10(29.4 \%)$ \\
PT3b & $8(23.5 \%)$ \\
Gleason score & $\mathrm{N}=34(100 \%)$ \\
$2-6$ & $7(20.5 \%)$ \\
$3+4$ & $10(29.4 \%)$ \\
$4+3$ & $6(17.6 \%)$ \\
$8-10$ & $9(26.4 \%)$ \\
T0 & $2(5.8 \%)$ \\
PSM rate & $\mathrm{N}=34(100 \%)$ \\
Overall & $1 \mathrm{I}(32.3 \%)$ \\
PT2 & $\mathrm{I}(2.9 \%)$ \\
PT3 & $\mathrm{I}(29.4 \%)$ \\
\hline A &
\end{tabular}

Abbreviations: ASAP, atypical small acinar proliferation; HGPIN, high-grade prostatic intraepithelial neoplasia; PSM, positive surgical margin.

and $68 \%$ of the cases, respectively. Mean LN yield was reported between six and 24..$^{11,15-22}$

PSM rate was $32.3 \%$ (2.9\% in pT2 and $29.4 \%$ in pT3 disease) in our series. Harty et $\mathrm{al}^{14}$ reported PSM rates as $12 \%$ and $79 \%$ in pT2 and pT3 disease, respectively. Pierorazio et al ${ }^{15}$ reported PSM rate as $8.3 \%$ in pT2 disease, and Gandaglia et a ${ }^{12}$ reported PSM rate as $60 \%$ in pT2 and pT3a disease. Others reported overall PSM rates between $12 \%$ and $48.8 \%{ }^{8,12,14-19}$ Our PSM rates seem to be similar to those in the published literature. Interestingly, pT0 disease was reported in two patients, and the pathology slides were re-reviewed by the pathology department without any change in the final diagnosis (Table 5).

In our series, at a mean follow-up of 27.8 months, BCR was detected in nine (26.4\%) patients. Punnen et $\mathrm{al}^{11}$ reported BCR as $79 \%$ at 2-year and $66 \%$ at 4 -year follow-up. Busch et a ${ }^{16}$ reported BCR as $41.4 \%$ at 3-year follow-up. Of the 34 patients in our study, four (11.8\%) received ART alone, four (11.8\%) received HT alone, and four (11.8\%) received ART+HT postoperatively. Gandaglia et a ${ }^{12}$ reported that $21.2 \%$ of 353 HRPC

Table 6 Oncologic outcomes of patients

\begin{tabular}{|c|c|c|c|c|c|}
\hline Follow-up & $\begin{array}{l}\text { First } \\
\text { month }\end{array}$ & $\begin{array}{l}\text { Third } \\
\text { month }\end{array}$ & $\begin{array}{l}\text { Sixth } \\
\text { month }\end{array}$ & $\begin{array}{l}\text { Ninth } \\
\text { month }\end{array}$ & $\begin{array}{l}\text { First } \\
\text { year }\end{array}$ \\
\hline \multicolumn{6}{|c|}{ Available patients: $\mathrm{N}=34(100 \%)$} \\
\hline \multicolumn{6}{|c|}{ BCR: 9 (26.4\%) } \\
\hline Overall & 5 & I & I & 0 & 1 \\
\hline pT2 & 0 & 0 & 0 & 0 & I \\
\hline pT3 & 5 & I & I & 0 & 0 \\
\hline
\end{tabular}

Abbreviation: $\mathrm{BCR}$, biochemical recurrence. 
Table 7 Postoperative urinary continence outcomes of the patients at follow-up

\begin{tabular}{|c|c|c|c|c|c|c|c|}
\hline & Preoperative & First day & First month & Third month & Sixth month & Ninth month & First year \\
\hline n (\%) & $34(100)$ & 34 & 34 & 34 & 34 & 34 & 34 \\
\hline Zero pads & $34(100)$ & 1 & 4 & 10 & 14 & 15 & 17 \\
\hline Safety pad & 0 & 16 & 10 & 9 & 9 & 8 & 6 \\
\hline I pad/day & 0 & 8 & 14 & 10 & 7 & 7 & 6 \\
\hline 2 pads/day & 0 & 5 & 2 & 2 & 2 & 2 & 3 \\
\hline$>2$ pads/day & 0 & 4 & 4 & 3 & 2 & 2 & 2 \\
\hline
\end{tabular}

patients who underwent RARP required additional cancer therapy after surgery. Of those, $15.9 \%$ required radiotherapy and $13.9 \%$ required androgen deprivation therapy. ${ }^{12}$ Currently, the mean follow-up time is limited in our series, and the need for additional therapy might change as follow-up increases.

In our series, during the perioperative period ( $0-30$ days), three minor (constipation/prolonged ileus [ $\mathrm{n}=1]$, prolonged anastomotic leakage $[\mathrm{n}=1]$, and urinary tract infection $[\mathrm{n}=1]$ ) and five major complications (intraoperative bladder injury $[\mathrm{n}=2]$ and rectum perforation $[\mathrm{n}=1]$, which were repaired intraoperatively, intensive care requirement [ $\mathrm{n}=1]$, and abdominal hematoma $[\mathrm{n}=1]$ ) complications occurred according to modified Clavien classification. We experienced rectal injury in one patient in our series, which we repaired intraoperatively. Postoperative follow-up was uneventful for this patient. No complication was detected during postoperative 31-90 days. Other authors reported complication rates between $4 \%$ and $30 \%$ in HRPC patients who underwent RARP. ${ }^{17,19,21,23}$ In these studies, lymphocele, ileus, anastomotic leakage, deep vein thrombosis, and rectal injury were among the reported complications. Ham et a ${ }^{19}$ reported rectal injury rate as $1.7 \%$. Lymphocele formation was reported between $2.5 \%$ and $6.6 \%$ in other studies..$^{19,21}$

Urinary continence and erectile function are the functional outcomes following RARP. Currently, the information about functional outcomes following RARP in HRPC patients is limited in the literature. Yuh et $\mathrm{al}^{24}$ reported 1-year urinary continence (zero to one safety pads/day) rate between $78 \%$ and $95 \%$ and erectile function recovery rate between $52 \%$ and $60 \%$. Yee et $\mathrm{al}^{25}$ reported their 1 -year pad-free continence rate as $84 \%$ in HRPC patients who underwent RARP. Preoperative erectile function status of the patient, postoperative adjuvant treatment requirement, NVB sparing (unilateral or bilateral), bladder neck preservation, and urethral length should all be considered seriously in the evaluation of postoperative functional outcomes. In our series, bilateral and unilateral NVB sparing was performed on $47 \%$ and $15 \%$, respectively. Only 13 patients (38\%) did not undergo NVB sparing. Of the 34 patients with 1-year follow-up, 17 (50\%) were fully continent (zero pads/day), six (17.7\%) wore one pad/day, three $(8.8 \%)$ wore two pads/day, and two (5.9\%) wore more than two pads/day. Of the 24 patients with no preoperative erectile dysfunction, 15 (44.1\%) had no erectile dysfunction at a mean follow-up of 1-year. Trifecta and pentafecta rates were $38 \%$ and $26 \%$, respectively. Preservation of the NVBs and postoperative adjuvant therapy administration are expected to affect functional outcomes.

Tissue characteristics might be different in HRPC patients compared with low-risk disease during performing of RARP. In addition, possibility of losing tissue of dissection might exist, and sufficient surgical experience might be essential. Therefore, we suggest gaining sufficient surgical experience in low-risk cases initially. Bulky disease and involvement of seminal vesicles or bladder neck could challenge the console surgeon. We demonstrated surgical differences comparatively in high-risk versus low-risk disease during performing of RARP (supplementary video).

Limited sample size, inclusion of more than one surgeon's experience, and being a retrospective and noncomparative study are the main limitations of our study.

Table 8 Postoperative erectile function outcomes of the patients at follow-up

\begin{tabular}{lllllll}
\hline IIEF scores & $\begin{array}{l}\text { Preoperative } \\
\text { n (\%) }\end{array}$ & First month & Third month & Sixth month & Ninth month & First year \\
\hline n (\%) & $34(100)$ & & & & & \\
No ED (IIEF score 22-25) & $24(70.5)$ & 0 & $5(14.7)$ & $9(26.4)$ & $10(29.4)$ & $15(44.1)$ \\
Mild (I7-2I) & $0(0)$ & 0 & $3(8.8)$ & $6(17.6)$ & $6(17.6)$ & $4(11.7)$ \\
Mild to moderate (I2-16) & I (2.9) & I (2.9) & $4(11.7)$ & $2(5.8)$ & I (2.9) & 0 \\
Moderate (8-II) & I (2.9) & 0 & $2(5.8)$ & $1(2.9)$ & $1(2.9)$ & $1(2.9)$ \\
Severe (5-7) & $8(23.5)$ & $33(97)$ & $20(57.1)$ & $16(47)$ & $16(47)$ & $14(41.1)$ \\
\hline
\end{tabular}

Abbreviations: IIEF, International Index of Erectile Function; ED, erectile dysfunction. 
Table 9 Trifecta and pentafecta outcomes

\begin{tabular}{lll}
\hline & $\begin{array}{l}\text { Proportion of } \\
\text { patients }\end{array}$ & $\%$ \\
\hline Trifecta outcomes at I year & 13 & 38 \\
Fully continent (no pad usage) & 17 & 50 \\
No ED* & 15 & 44 \\
BCR-free state** & 31 & 91 \\
Pentafecta outcomes at I year & 9 & 26 \\
No perioperative complications*** & 26 & 76 \\
Negative SMs & 23 & 68 \\
\hline
\end{tabular}

Notes: *Potency was defined as the ability to achieve and maintain satisfactory erections firm enough for sexual intercourse in $>50 \%$ of attempts, with or without the use of phosphodiesterase type 5 . If patients required a vacuum erection device, penile injections, or transurethral alprostadil for intercourse, they were not considered to be potent; **BCR was defined as two consecutive serum prostate-specific antigen levels of $>0.2 \mathrm{ng} / \mathrm{mL}$; $* * *$ according to modified Clavien-Dindo classification.

Abbreviations: ED, erectile dysfunction; BCR, biochemical recurrence; SM, surgical margin.

\section{Conclusion}

In conclusion, according to our experience, RARP in HRPC is a safe procedure with satisfactory oncologic and functional outcomes in the short term.

\section{Disclosure}

This study was presented by Dr Canda as a poster during the European Robotic Urology Symposium (ERUS), which was held on 17-19 September 2014 in Amsterdam, the Netherlands. Dr Canda is a member of the Robotic Urology Working Group of the Young Academic Urologists (YAU) of the European Association of Urology (EAU). The other authors report no conflicts of interest in this work.

\section{References}

1. Jemal A, Siegel R, Ward E, et al. Cancer statistics, 2008. CA Cancer J Clin. 2008;58:71-96.

2. Cooperberg MR, Cowan J, Broering JM, Carroll PR. High-risk prostate cancer in the United States, 1990-2007. World J Urol. 2008;26: 211-218.

3. D'Amico AV, Whittington R, Malkowicz SB, et al. Biochemical outcome after radical prostatectomy, external beam radiation therapy, or interstitial radiation therapy for clinically localized prostate cancer. JAMA. 1998;280(11):969-974.

4. Gonzalez JR, Laudano MA, McCann TR, McKiernan JM, Benson MC. A review of high-risk prostate cancer and the role of neo-adjuvant and adjuvant therapies. World J Urol. 2008;26:475-480.

5. Lau WK, Bergstralh EJ, Blute ML, Slezak JM, Zincke H. Radical prostatectomy for pathological Gleason 8 or greater prostate cancer: influence of concomitant pathological variables. J Urol. 2002;167:117-122.

6. Thompson IM, Carroll PR, Carducci MA. Recommendations for defining and treating high risk localized prostate cancer. J Urol. 2006;176(6 Pt 2): S6-S10; quiz S3-S5.

7. Sooriakumaran P, Nyberg T, Akre O, et al. Comparative effectiveness of radical prostatectomy and radiotherapy in prostate cancer: observational study of mortality outcomes. BMJ. 2014;348:g1502.

8. Cooperberg MR, Vickers AJ, Broering JM, Carroll PR. Comparative risk-adjusted mortality outcomes after primary surgery, radiotherapy, or androgen-deprivation therapy for localized prostate cancer. Cancer. 2010;116:5226-5234.
9. Kawachi MH. Counterpoint: robot-assisted laparoscopic prostatectomy: perhaps the surgical gold standard for prostate cancer care. J Natl Compr Canc Netw. 2007;5:689-692.

10. Canda AE, Atmaca AF, Akbulut Z, et al. Results of robotic radical prostatectomy in the hands of surgeons without previous laparoscopic radical prostatectomy experience. Turk J Med Sci. 2012;42(Suppl 1): 1338-1346.

11. Punnen S, Meng MV, Cooperberg MR, Greene KL, Cowan JE, Carroll PR. How does robot-assisted radical prostatectomy (RARP) compare with open surgery in men with high-risk prostate cancer? BJU Int. 2013;112(4):E314-E320.

12. Gandaglia G, Abdollah F, Hu J, et al. Is robot-assisted radical prostatectomy safe in men with high-risk prostate cancer? Assessment of perioperative outcomes, positive surgical margins, and use of additional cancer treatments. $J$ Endourol. 2014;28(7):784-791.

13. Partin AW, Mangold LA, Lamm DM, Walsh PC, Epstein JI, Pearson JD. Contemporary update of prostate cancer staging nomograms (Partin Tables) for the new millennium. Urology. 2001;58:843-848.

14. Harty NJ, Kozinn SI, Canes D, Sorcini A, Moinzadeh A. Comparison of positive surgical margin rates in high risk prostate cancer: open versus minimally invasive radical prostatectomy. Int Braz J Urol. 2013;39(5):639-646; discussion 647-648.

15. Pierorazio PM, Mullins JK, Eifler JB, et al. Contemporaneous comparison of open vs minimally-invasive radical prostatectomy for high-risk prostate cancer. BJU Int. 2013;112(6):751-757.

16. Busch J, Magheli A, Leva N, et al. Matched comparison of outcomes following open and minimally invasive radical prostatectomy for highrisk patients. World J Urol. 2014;32(6):1411-1416.

17. Jayram G, Decastro GJ, Large MC, et al. Robotic radical prostatectomy in patients with high-risk disease: a review of short-term outcomes from a high-volume center. J Endourol. 2011;25:455-457.

18. Silberstein JL, Su D, Glickman L, et al. A case-mix-adjusted comparison of early oncological outcomes of open and robotic prostatectomy performed by experienced high volume surgeons. BJU Int. 2013;111(2): 206-212.

19. Ham WS, Park SY, Rha KH, Kim WT, Choi YD. Robotic radical prostatectomy for patients with locally advanced prostate cancer is feasible: results of a single-institution study. $J$ Laparoendosc Adv Surg Tech A. 2009; 19:329-332.

20. Sagalovich D, Calaway A, Srivastava A, Sooriakumaran P, Tewari AK. Assessment of required nodal yield in a high risk cohort undergoing extended pelvic lymphadenectomy in robotic-assisted radical prostatectomy and its impact on functional outcomes. BJU Int. 2013;111: 85-94.

21. Yuh BE, Ruel NH, Mejia R, Wilson CM, Wilson TG. Robotic extended pelvic lymphadenectomy for intermediate- and high-risk prostate cancer. Eur Urol. 2012;61:1004-1010.

22. Jung JH, Seo JW, Lim MS, et al. Extended pelvic lymph node dissection including internal iliac packet should be performed during robotassisted laparoscopic radical prostatectomy for high-risk prostate cancer. J Laparoendosc Adv Surg Tech A. 2012;22:785-790.

23. Rogers CG, Sammon JD, Sukumar S, Diaz M, Peabody J, Menon M. Robot assisted radical prostatectomy for elderly patients with high risk prostate cancer. Urol Oncol. 2013;31(2):193-197.

24. Yuh B, Artibani W, Heidenreich A, et al. The role of robot-assisted radical prostatectomy and pelvic lymph node dissection in the management of high-risk prostate cancer: a systematic review. Eur Urol. 2014;65(5): 918-927.

25. Yee DS, Narula N, Amin MB, Skarecky DW, Ahlering TE. Robotassisted radical prostatectomy: current evaluation of surgical margins in clinically low-, intermediate-, and high-risk prostate cancer. $J$ Endourol. 2009;23(9):1461-1465. 
Robotic Surgery: Research and Reviews

Dovepress

\section{Publish your work in this journal}

Robotic Surgery: Research and Reviews is an international, peer reviewed, open access, online journal publishing original research, commentaries, reports, and reviews on the theory, use and application of robotics in surgical interventions. Articles on the use of supervisory-controlled robotic systems, telesurgical devices, and shared-control systems are

Submit your manuscript here: http://www.dovepress.com/robotic-surgery-research-and-reviews-journal invited. The manuscript management system is completely online and includes a very quick and fair peer review system, which is all easy to use. Visit http://www.dovepress.com/testimonials.php to read real quotes from published authors. 